\title{
PROCESS AND ACCELERATED AGING TEST OF GANG BONDING FOR GOLD-PLATED TAB OUTER LEADS
}

\author{
M. NITTA, T. TSUGE, Y. HIKI and R. KATO \\ Computer Engineering Division, Nippon Electric Co., Ltd., 1-10, Nissin-cho, Fuchu-City, Tokyo, 183 \\ Japan
}

\begin{abstract}
This paper presents the evaluation results of thermocompression GANG Bonding of gold-plated TAB outer leads to three kinds of metallized ceramic substrates. Gold-Selective Plating (GSP) substrates for multi-chip package, Thick Film (TF) substrates for multi-chip package and Single Chip Packages (SCP) which have a trimetal combination of refractory metal (tungsten), Nickel and Gold.

The bonding parameters such as the bonding tool (thermode) temperature, pressure, bonding time and preheat temperature were examined on each substrate to get optimum values. As the result, a relation between pull strength and the lead deformation shows that the TAB leads should be bonded with 15-65 percent deformation, the recommended parameters are; the tool temperature of $380-430^{\circ} \mathrm{C}$, the bonding pressure ranging from 35 to $45 \mathrm{~kg} / \mathrm{mm}^{2}$, with the preheat temperature of $150^{\circ} \mathrm{C}$ and the bonding time from 1.0 to 2.5 seconds.

The evaluation of initial bondability shows that TAB GANG Bonding has the capability of excellent bonding strength; above 120 grams with standard deviation of less than 20 grams, and the necessity of OLB pads flatness; less than $\pm 12 \mu \mathrm{m}$ for one ounce copper lead. The normal storage of the substrate and the lead does not affect the bondability. And the results of accelerated aging test of $125^{\circ} \mathrm{C}, 150^{\circ} \mathrm{C}$ and $175^{\circ} \mathrm{C}$ for more than 8,000 hours show that a lifetime of greater than 70 years at $65^{\circ} \mathrm{C}$ operating temperature is predicted. The effective activation energy for the pull strength degradation is $0.86-1.05 \mathrm{eV}$. This is in reasonable agreement with predictions for interdiffusion of $\mathrm{Cu}-\mathrm{Au}$. And no significant degradation of the electric resistance was observed on the GSP samples.

The feasibility and the high reliability of the GANG Bonding for gold-plated TAB outer leads were confirmed.
\end{abstract}

\section{INTRODUCTION}

The Tape Automated Bonding (TAB) technology is continuously evolving since its concept was announced. ${ }^{1}$ The TAB technology offers many advantages such as an automated low cost assembly of microelectronics, pretestability of STATIC/DYNAMIC chip test and burn-in on tape and high reliability. ${ }^{2}$

Recently, TAB is applied to large scale integrated circuits (LSI) and very large scale interated circuits (VLSI) which have a large number of leads as many as 24-120. GANG Bonding, that is simultaneous bonding of the large number of leads, has been investigated for practical use. GANG Bonding has a capability of accomplishing a high speed assembly of microcircuits, and increasing the reliability of bonding.

The purpose of this work is to establish the thermocompression (T.C.) GANG Bonding process for gold-plated TAB outer leads on gold-metallized substrates, and to evaluate the reliability of the interconnections.

\section{BONDING EXPERIMENTS}

\subsection{Experiment Materials}

NEC TAB chips mounted on a gold plated lead frame which is a normal product were prepared for the experiments. Table I lists some interesting data for outer lead bondings.

In order to examine the dependence of bondability on the different substrate metallizations, three kinds of metallization were chosen as follows: 1) GSP which has Ti-Cu-Au Outer Lead Bonding (OLB) pads above two

TABLE I

Lead frame for the experiment

Material

Lead thickness

Lead width

Pitch
$10 \mathrm{Z}$ Rolled copper with plated gold $38 \sim 54 \mu \mathrm{m}$ $130 \sim 160 \mu \mathrm{m}$ at OLB $500 \mu \mathrm{m}$ for $24 / 40$ TAB leads $300 \mu \mathrm{m}$ for 80 TAB leads 
TABLE II

Substrates examined

\begin{tabular}{llll}
\hline & (1) GSP & (2) $\mathrm{TF}$ & (3) SCP \\
\hline Metallization & Ti/Cu/Au & ESL8880 & W/Ni/Au \\
Au-thickness & $1 \sim 2 \mu \mathrm{m}$ & $10 \sim 15 \mu \mathrm{m}$ & $0.5 \sim 2.0 \mu \mathrm{m}$ \\
OLB PAD thickness & $25 \sim 35 \mu \mathrm{m}$ & - & $8 \sim 13 \mu \mathrm{m}$ \\
Unevenness 24-PAD & $4.8 \pm 1.4 \mu \mathrm{m}$ & $5.5 \pm 1.5 \mu \mathrm{m}$ & $4.0 \pm 1.5 \mu \mathrm{m}$ \\
40-PAD & $6.0 \pm 1.5 \mu \mathrm{m}$ & $5.7 \pm 1.6 \mu \mathrm{m}$ & $5.0 \pm 2.2 \mu \mathrm{m}$ \\
80-PAD & $7.2 \pm 1.5 \mu \mathrm{m}$ & - & $10.5 \pm 2.8 \mu \mathrm{m}$ \\
\hline
\end{tabular}

signal layers, 2) TF with ESL 8880 OLB pads and 3) SCP which has W-Ni-Au OLB pads.

Some interesting data are shown in Table II.

In Table II, the deposited Au-thickness and the pad thickness were measured by a fluorescent $\mathrm{X}$-ray microarea thickness gauge or a surface stylus.

\subsection{Initial Bonding Experiments}

The GANG Bonding experiments were tried by using a lead frame bonder. This bonder permits operation with varied bonding condition as the tool temperature (100$\left.600^{\circ} \mathrm{C}\right)$, pressure $(5-60 \mathrm{~kg})$, bonding time $(0-10 \mathrm{sec}$.) and preheat temperature $\left(50-350^{\circ} \mathrm{C}\right)$.

A " $L_{27}\left(3^{13}\right)$ " matrix of the experiment design method was applied for the experiments to reduce a number of parameter combinations. Each level of the parameter values were shown in Table III.

TABLE III

Experiment parameter

\begin{tabular}{llll}
\hline Parameters & Level I & Level II & Level III \\
\hline Tool temp. ${ }^{\circ} \mathrm{C}$ & $250 / 300$ & $350 / 375$ & 450 \\
Pressure $\mathrm{kg} / \mathrm{mm}^{2}$ & 11 & $41 / 29$ & $64 / 46$ \\
Bonding time sec. & 1.0 & $3.0 / 2.5$ & $6.0 / 4.0$ \\
Preheat temp. ${ }^{\circ} \mathrm{C}$ & 100 & 150 & 200 \\
\hline
\end{tabular}

A total of 432 TAB chips (about 20,000 leads) were bonded with the varied parameter combinations according to the matrix. All bonded leads were checked visually and lead deformation were measured at sampling points of the each chip by using a light section microscope. Then bond pull strength of the individual lead was obtained by a universal bond tester, and failure modes were determined by a microscope. Figure 1 shows the pull test method and the failure mode classification.

As the results of the data analysis, the tool temperature and the pressure are more contributive parameters for the bondability, and no significant change of the bondability was noticed among the

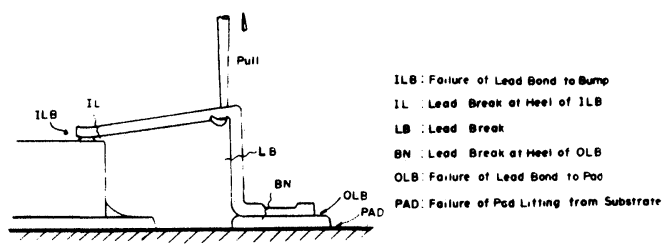

FIGURE 1 Pull test method and failure mode.
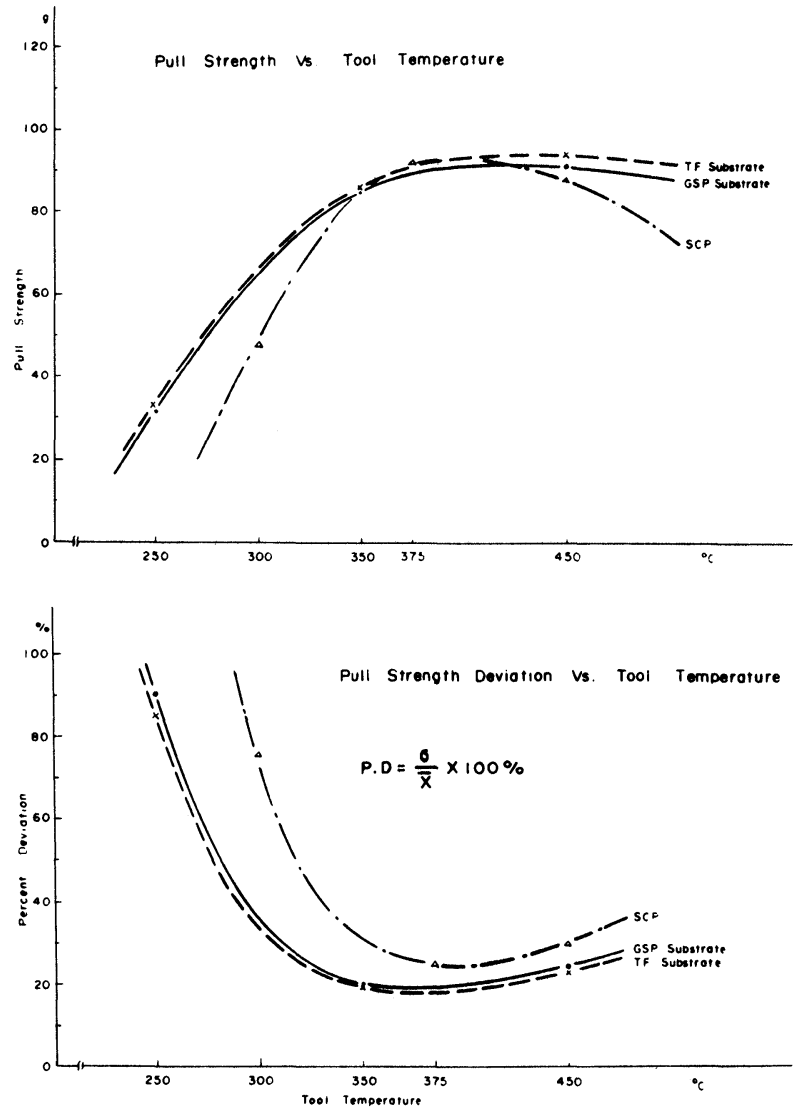

GRAPH 1 Effects of tool temperature. 
different metallized substrates in the each varied parameter combination.

Graph 1 shows the effects of the tool temperature for the pull strength and the percent deviation $(\sigma / \overline{\mathrm{X}} \times$ $100 \%)$ of the strength for three substrate metallizations. The curves in the graph show that the tool temperature of around $400^{\circ} \mathrm{C}$ is recommended to obtain a higher pull strength with a less deviation. The effects of the pressure are shown in Graph 2. A little variation is found among the substrate metallizations which are dissimilar in a hardness of the OLB pads. As expected, the lead deformation is proportionate to the pressure. Graph 3 indicates the pull strength under the influence of the preheat temperature and the bonding time.

Graph 4 shows a interaction between the tool temperature and the pressure in GSP (similar in other substrates). If the tool temperature is set high enough, the pressure has a optimum value. However, when the tool temperature is lower $\left(\leq 350^{\circ} \mathrm{C}\right)$, a higher pressure is required to increase the pull strength. Graph 5 shows the relation between the pull strength and the percent deformation of the leads which were bonded with the tool temperature from 350 to $450^{\circ} \mathrm{C}$. From Graph 5, when the percent deformation is less than $15 \%$, all failure modes are OLB failure with low pull strength. Some low pull strengths are also observed associated with $\mathrm{BN}$ failure, if the percent deformation become more than $70 \%$.
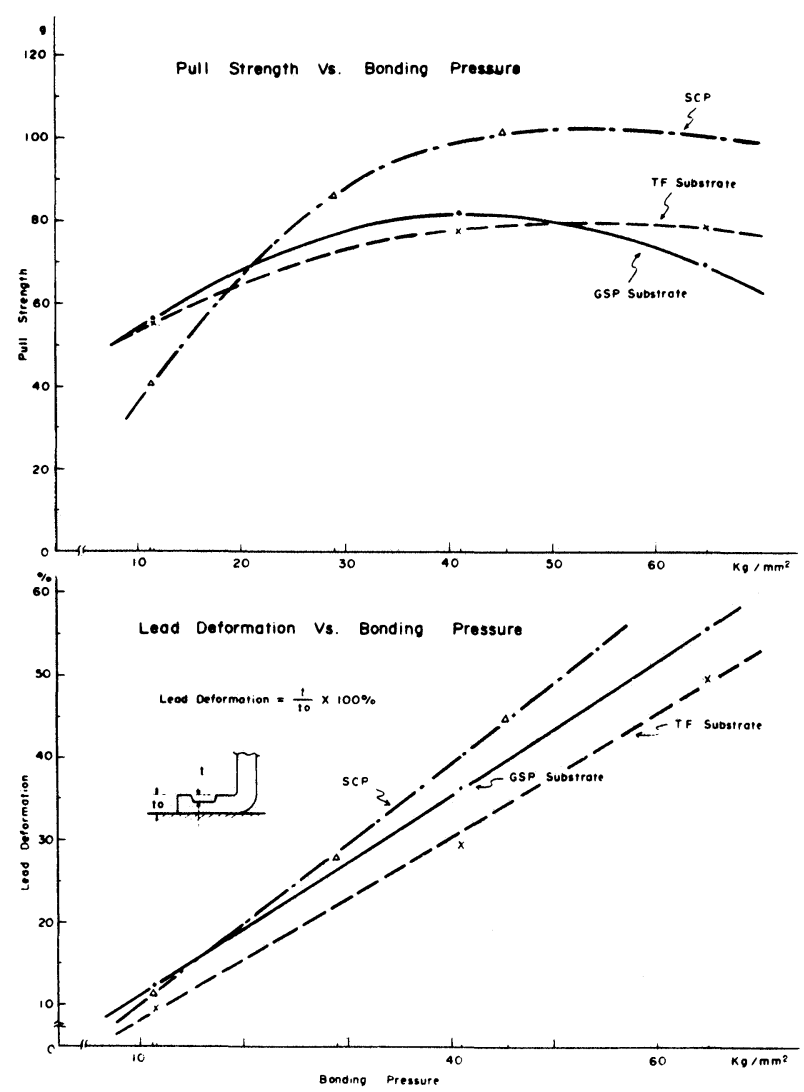

GRAPH 2 Effects of bonding pressure.
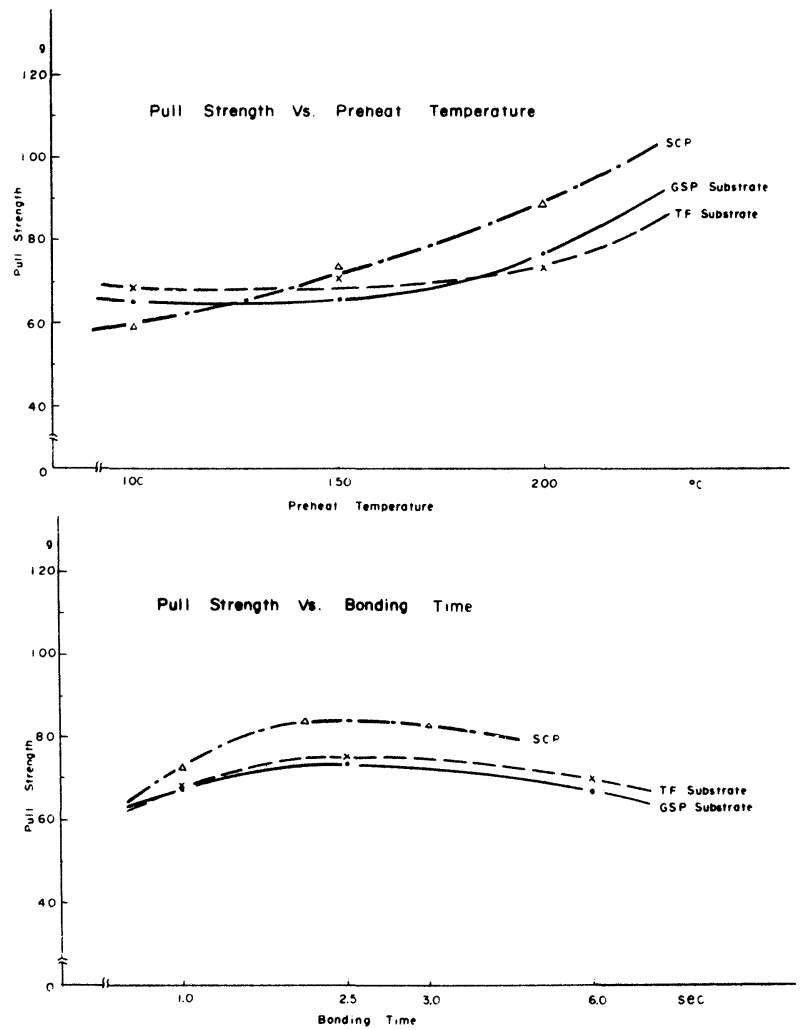

GRAPH 3 Effects of preheat temperature and bonding time.
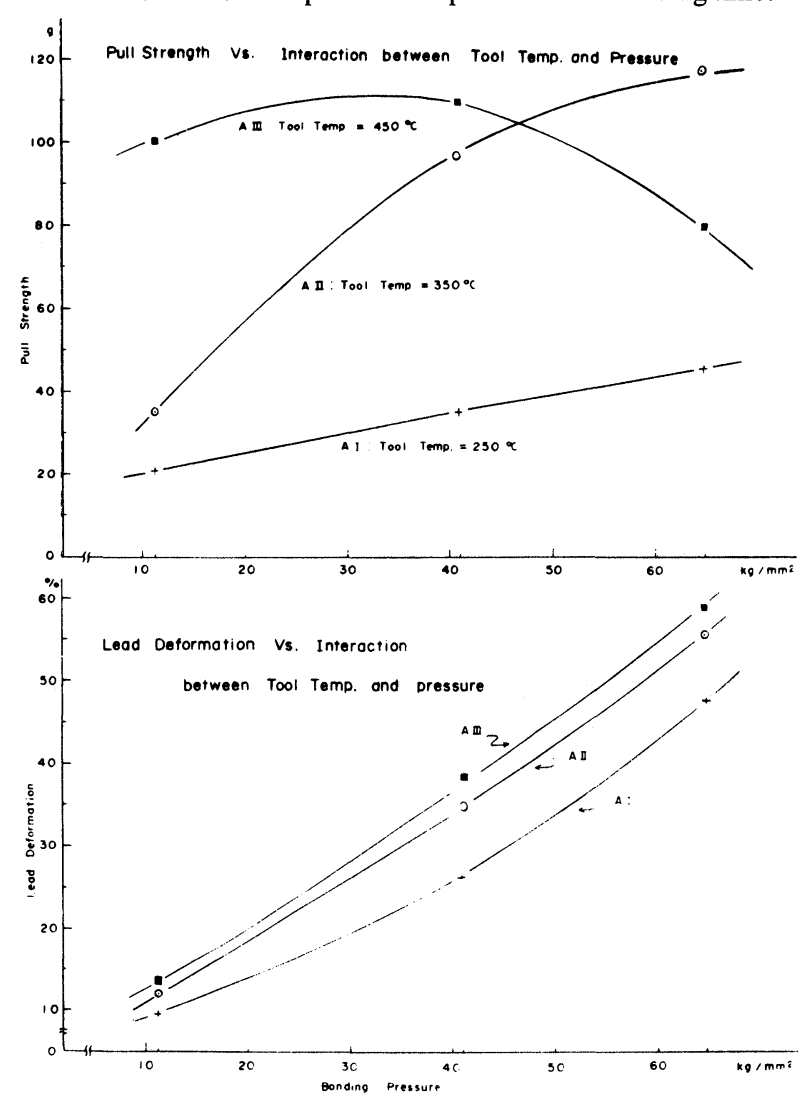

GRAPH 4 Effects of interaction between tool temperature and pressure. 

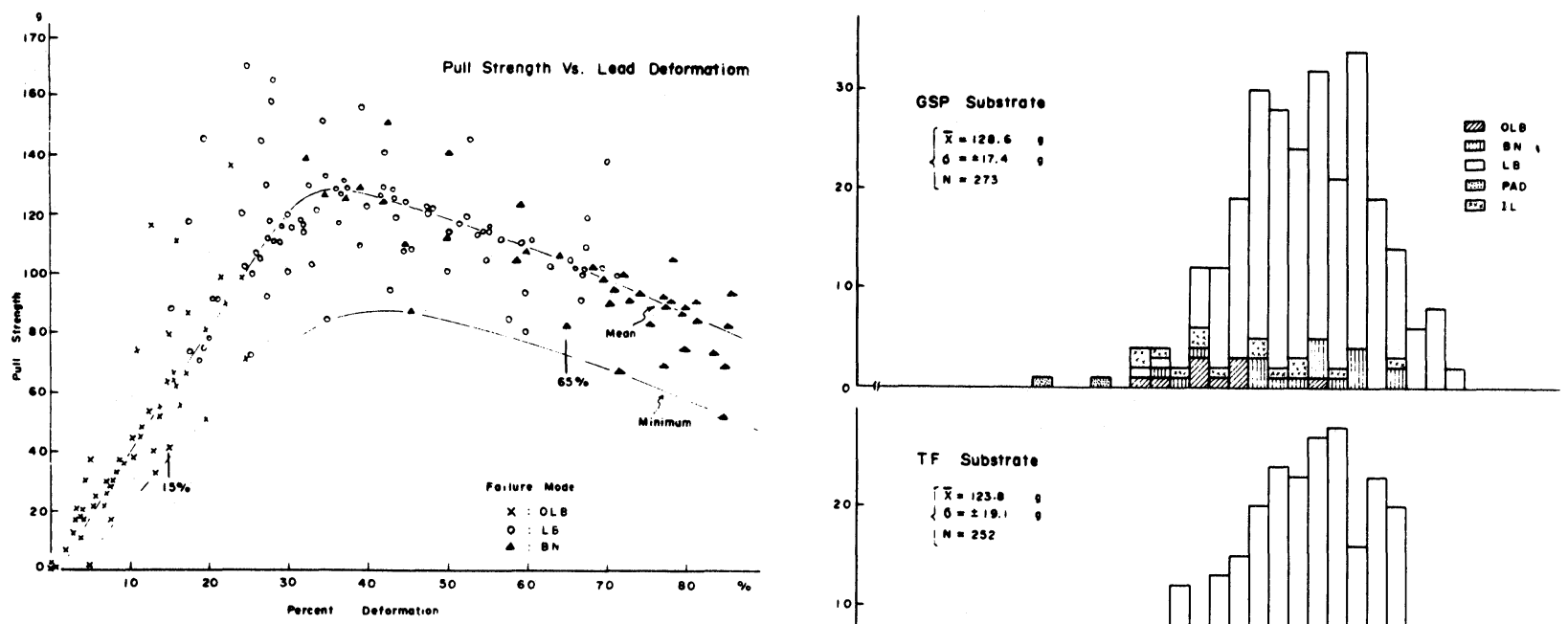

GRAPH 5 Relation between pull strength and lead deformation.

From the mean value point of view, maximum pull strength is at around $35 \%$ deformation and from the minimum value point of view, the maximum pull strength is at $35-55 \%$ deformation. To get high reliability of bonding, the minimum of the initial bonding strength was determined to be 40 grams at the low percent deformation and 80 grams at the high percent deformation; namely the leads should be bonded at $15-65 \%$ deformation with sufficient tool temperature.

As the result of the above evaluations, the recommended parameters for a proper GANG Bonding are as follows:
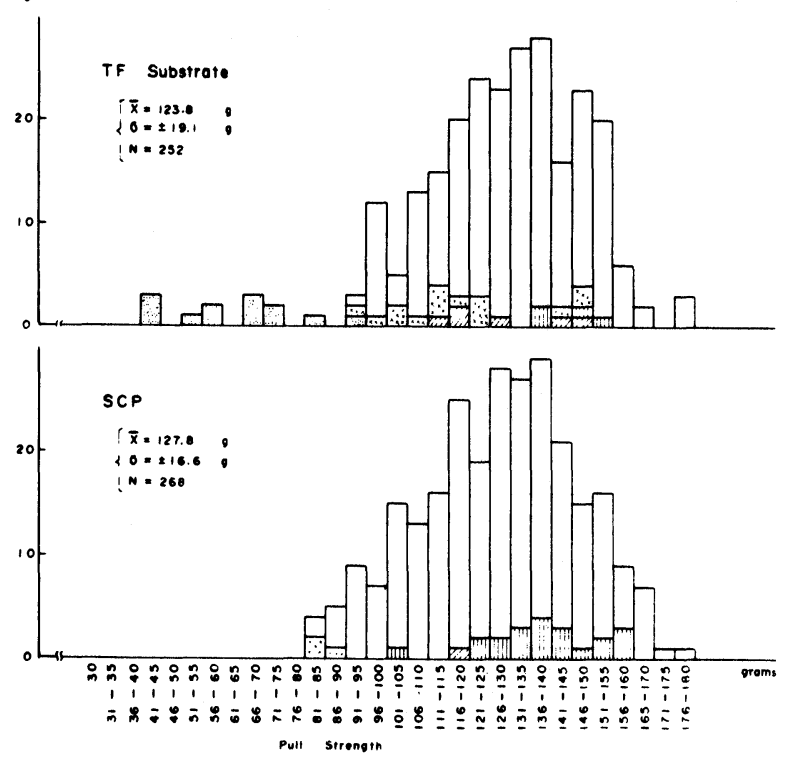

GRAPH 6 Histograms of initial bondability.

TABLE IV

Recommended bonding parameter

\begin{tabular}{ll}
\hline Tool temp. & $400 \pm 20{ }^{\circ} \mathrm{C}$ \\
Pressure & $35 \sim 45 \mathrm{~kg} / \mathrm{mm}^{2}$ \\
Bonding time & $1.0 \sim 2.5 \mathrm{sec}$. \\
Preheat temp. & $\simeq 150^{\circ} \mathrm{C}$ \\
\hline
\end{tabular}

In order to evaluate the initial bondability, the TAB chips were bonded on each substrate of the different metallization by using the recommended parameters. Graph 6 shows the histograms of initial bondability and those data show excellent bonding strength such as the mean value of above 120 grams with the standard deviation of less than 20 grams. Photo 1 shows a SEM picture of typical bond.

The results of evaluation also show the importance of

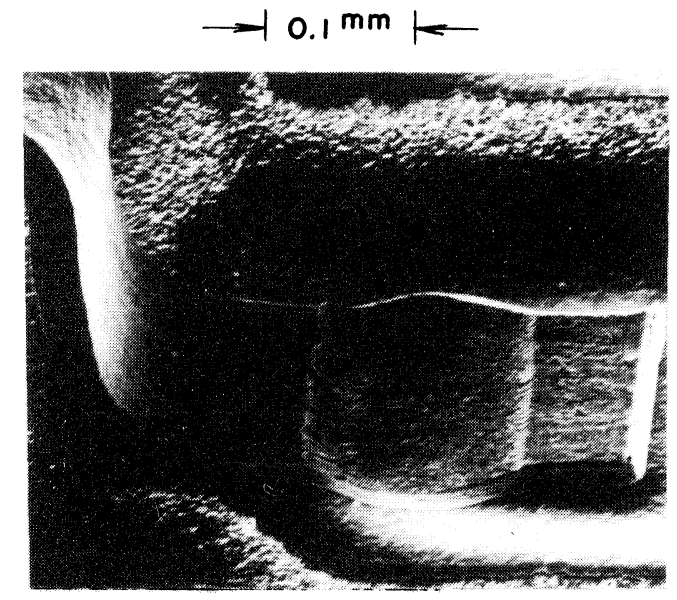

PHOTO 1 SEM picture of typical bond. 


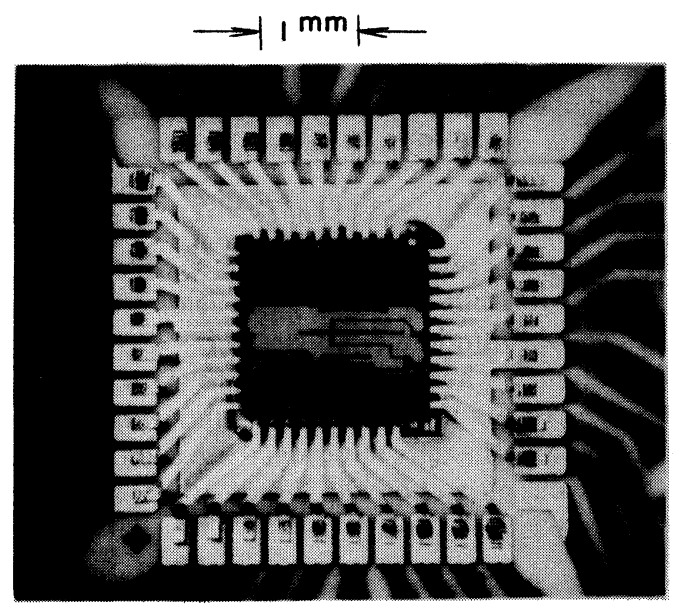

PHOTO 2 Bonding shape of a rejected sample.

flatness among OLB pad tops. In the experiment, three samples were rejected by reason of the planarity problem. One of them was caused by a protuberance of dielectric layer under the OLB pad, the other two were substrate warping of the SCP. When a rigid bonding tool is used for the GANG Bonding, there is no provision for unevenness/pressure adjustment at each individual bond site so that it is considered that the unevenness among OLB pad tops should be compensated by only a deformation of bonded materials. From the relation between the deformation and the pull strength (15-65\% deformation), an allowance value of the unevenness could be estimated roughly as less than $25 \mu \mathrm{m}$. Photo 2 and Graph 7 show

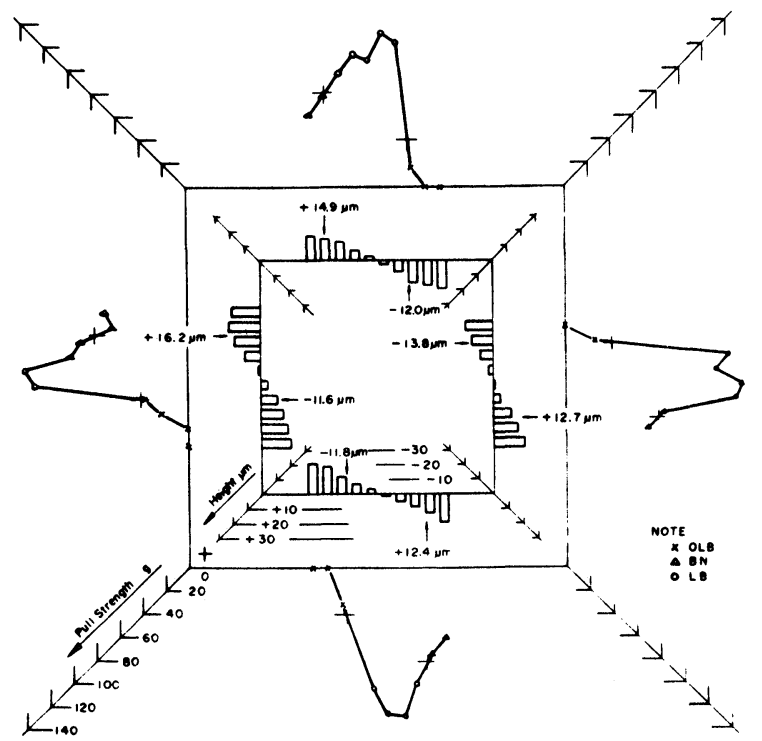

GRAPH 7 Analysis of planarity problem. a bonding shape and an evaluation result respectively of a rejected sample. They also indicate that the flatness of around $25 \mu \mathrm{m}$ or less is required to get a specified strength. Otherwise, the OLB pad top flatness should not exceed about $\pm 12 \mu \mathrm{m}$ for a suitable GANG Bonding.

\subsection{Shelf Life}

The three kinds of substrates and TAB chips on a tape were heated at $175^{\circ} \mathrm{C}$ for 48 hours in a circulated air oven prior to bonding. The objective of this test was to make sure of the bondability for storage and heat-stress prior to bonding. After the heating, the TAB chips were bonded to each substrate by using the recommended parameters. Then the individual leads of the chip were pull tested and the strength/failure mode were noted.

Typical results of the bondability are shown in Graph 8. No deteriorations were observed on the SCP samples and the TF samples. However, the GSP samples show a slight decrease of a mean value of the strength associated with low pull strength OLB failures, but they are still acceptable. It is considered that the degradation in bondability of the GSP substrate would be caused by the oxidation of $\mathrm{Cu}$ of the OLB pad which was diffused through $\mathrm{Au}^{3}$ To remove the $\mathrm{Cu}$ oxide stains from the OLB pad surface, a chemical cleaning of the aged GSP was tried by pickling in dilute $\mathrm{HCl}(36 \%$ $\left.\mathrm{HCl}+5 \mathrm{H}_{2} \mathrm{O}\right)$. As a result, the bondability of the aged GSP sample was fully improved as shown in Graph 8.

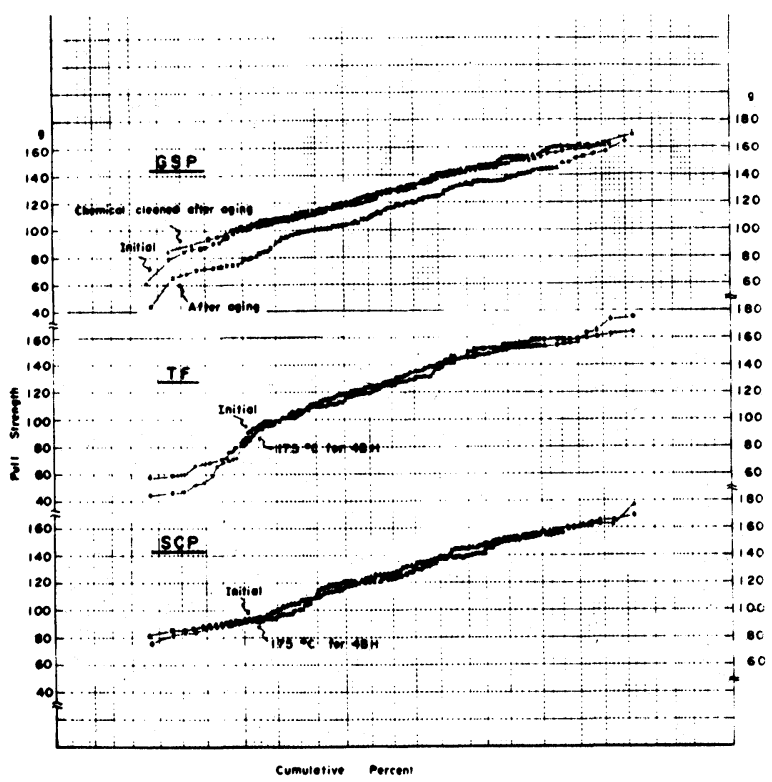

GRAPH 8 Pull strength of aged samples. 
In any case, using the activation energy of $0.9 \mathrm{eV}$ reported for grain boundary diffusion of $\mathrm{Cu}$ in $\mathrm{Au}^{4}$ and the result of experiment $\left(175^{\circ} \mathrm{C}, 48 \mathrm{H}\right)$, the shelf life of the substrates and TAB chips could be estimated to be more than 40 years at $50^{\circ} \mathrm{C}$.

\section{ACCELERATED AGING TEST}

\subsection{Pull Strength}

The reliability test samples were bonded to the metallized substrates by using the recommended parameters. The samples were aged in circulated air ovens at $125^{\circ} \mathrm{C}, 150^{\circ} \mathrm{C}$ and $175^{\circ} \mathrm{C}$ for above 8000 hours. During the aging test, the leads on each substrate were pull tested at regular time intervals and the strength and its failure mode of each lead were noted for an evaluation.

No significant change of the strength and the failure mode were observed until 500 hours for TF samples, 1000 hours for the GSP samples and 3000 hours for the SCP samples at any temperature. However, at the GSP and the TF samples, aged at $175^{\circ} \mathrm{C}$ for more than 2000 hours, many low pull strength failures were observed associated with a change of the failure mode. The failure mode was mainly changed from the LB failure to the OLB failure.

Graph 9 shows a degradation behavior of the pull strength on GSP as time proceeds. The degradation time is clearly faster at higher temperatures. On the samples aged at $175^{\circ} \mathrm{C}$, the degradation occurred rapidly during $1000-2000 \mathrm{~h}$, and the rate becomes low after $3000 \mathrm{~h}$. A similar degradation was observed during $3500-8000 \mathrm{~h}$ at $150^{\circ} \mathrm{C}$ aging. As for the $125^{\circ} \mathrm{C}$,

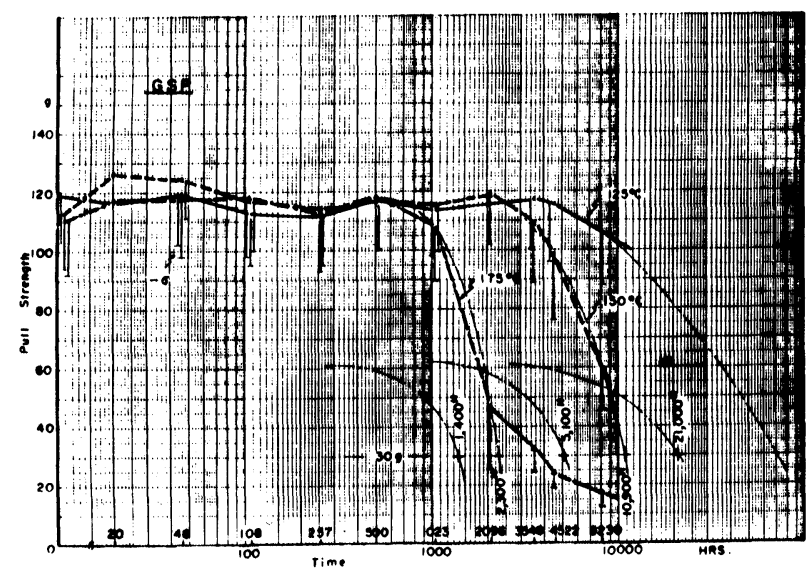

GRAPH 9 Degradation of pull strength after temperature aging. the aging samples, however, did not show a significant degradation up to 8000 hours.

In order to estimate life time, an Arrhenius-type degradation was supposed as defined by:

$$
t=K \exp (E / K T)
$$

This assumption predicts a straight line relationship if a common logarithm of the life time is plotted versus reciprocal absolute temperature; $1 / T \cdot K$. And the life time is defined when the mean minus three sigma $(\bar{x}-$ $3 \sigma$ ) value crosses the 30 gram strength limit. These definitions and the data in Graph 9 are used to construct the Arrhenius plots shown in Graph 10. Its equation of the lifetime is given by:

$$
\begin{aligned}
t(30 \mathrm{~g} \geq \bar{x}-3 \sigma) & = \\
6.49 & \times 10^{-7} \exp (0.83 / K T) \text { (hours) }
\end{aligned}
$$

Where $t(30 \mathrm{~g} \geqslant \bar{x}-3 \sigma)$ is the time required for the appearance of 0.13 percent unacceptable bond for 30 gram limit. From an extrapolation of the Eq. (2), a life time of the bonding on GSP is expected for 170 years at $65^{\circ} \mathrm{C}$.

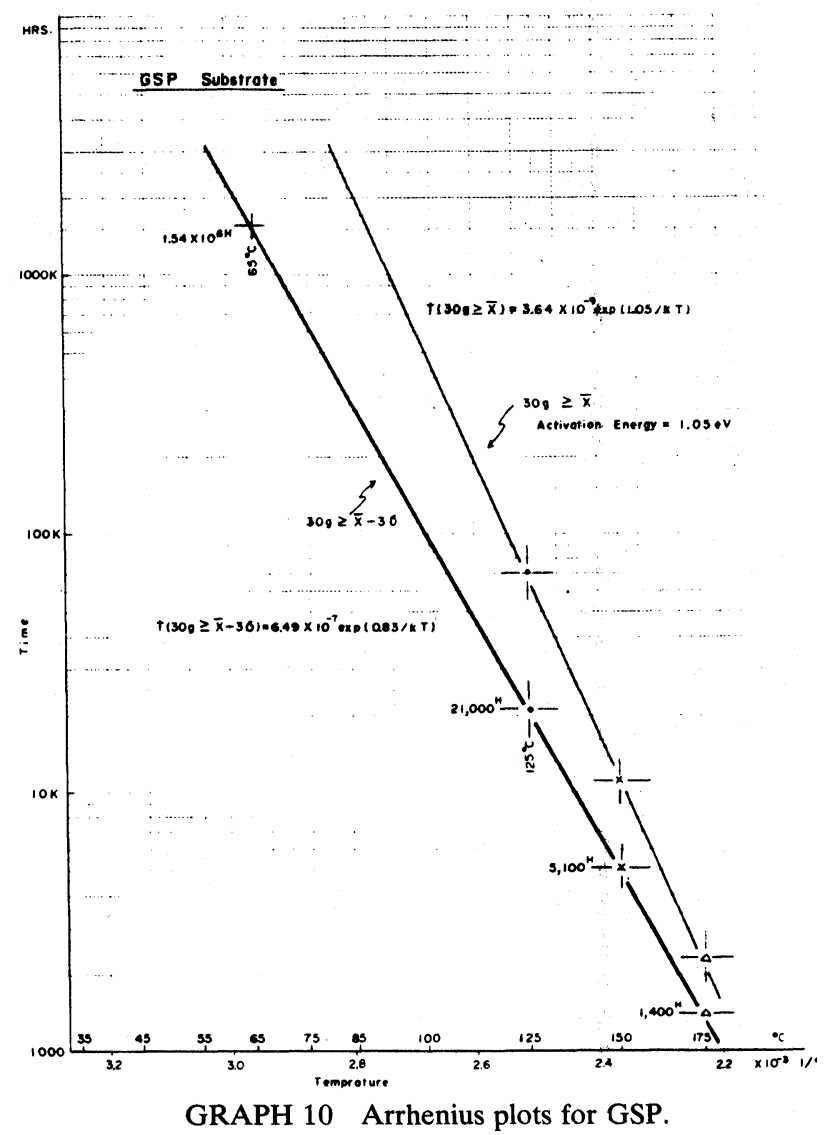


To consider the degradation of mean value, a mean lifetime is defined as the time required at a given temperature for the mean value to cross 30 grams. The mean lifetime is described by:

$$
\begin{aligned}
& t(30 \mathrm{~g} \geq \bar{x})= \\
& 3.64 \times 10^{-9} \exp (1.05 / K T) \text { (hours) }
\end{aligned}
$$

This is also shown in Graph 10 as curve $t(30 \mathrm{~g} \geq \bar{x})$. Its effective activation energy of $1.05 \mathrm{eV}$ is somewhat larger than that of the Eq. (2). However, the effective activation energy is in reasonable agreement with the activation energy of $1.1 \mathrm{eV}$ reported for $\mathrm{Cu}-\mathrm{Au}$ interdiffusion. ${ }^{5}$

A similar behavior was also obtained on TF of ESL 8880 OLB pads as shown in Graph 11. The degradation of the pull strength, however, was a little faster than the GSP samples at each aging temperature, associated with some thick film pad peelings of low pull strength. The time and temperature shown in Graph 11 are used to construct the Arrhenius plots shown in Graph 12. For the TF samples, the resulting equation is:

$$
\begin{aligned}
t(30 \mathrm{~g} \geq \bar{x}-3 \sigma) & = \\
3.18 & \times 10^{-6} \exp (0.76 / K T) \text { (hours) }
\end{aligned}
$$

Where $t(30 \mathrm{~g} \geq \bar{x}-3 \sigma)$ is the time required for the appearance of 0.13 percent unacceptable bond for 30 grams limit. Extrapolation of the Eq. (4) predicts a lifetime of greater than 75 years at $65^{\circ} \mathrm{C}$. The activation energy of the Eq. (4) is smaller than that of the GSP. It is considered that the degradation of the pull strength of the TF samples included a decline of the thick film adhesion during aging. A mean lifetime for the TF samples is given by:

$t(30 \mathrm{~g} \geq \bar{x})=$

$$
4.02 \times 10^{-7} \exp (0.86 / K T) \text { (hours) }
$$

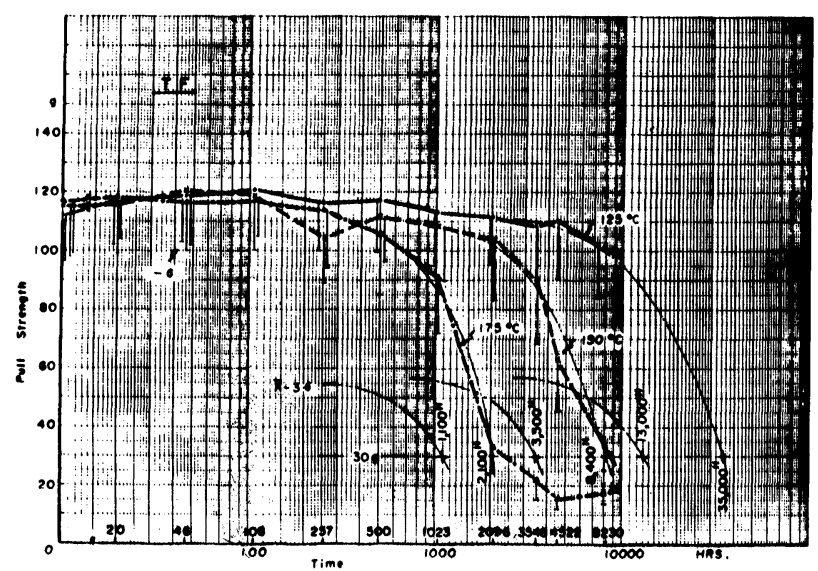

GRAPH 11 Degradation of pull strength after temperature aging.

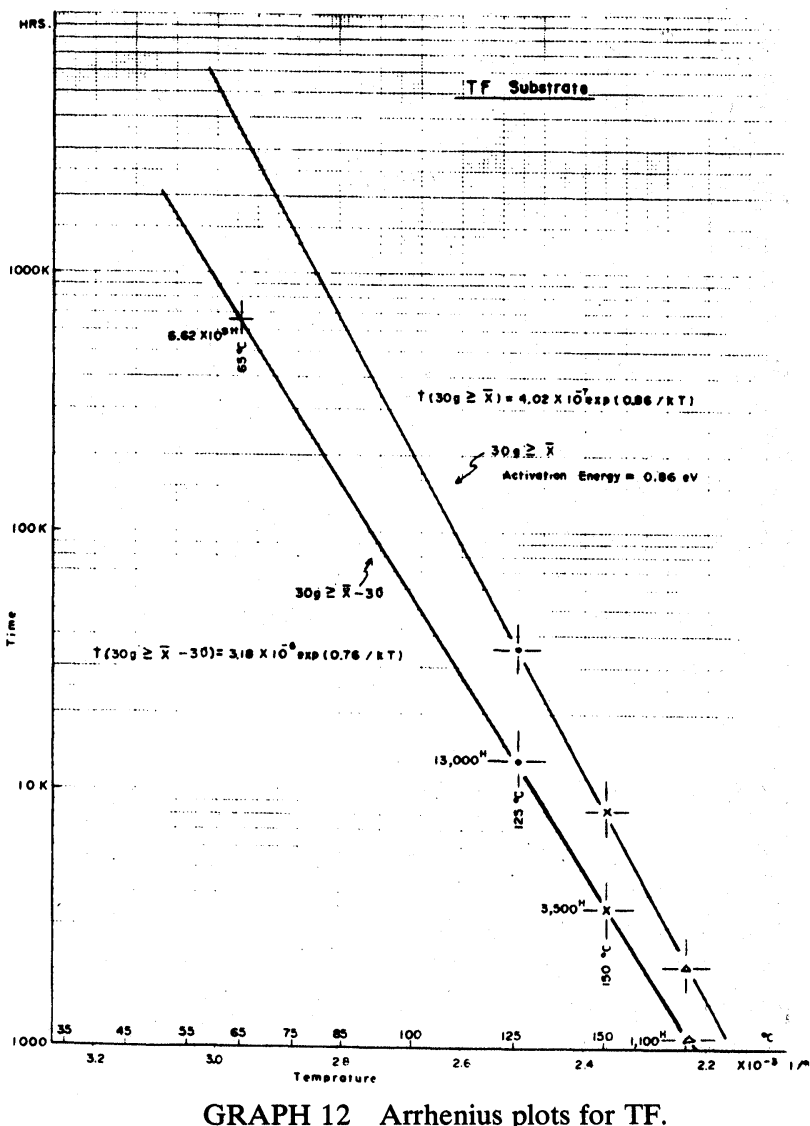

The effective activation energy of $0.86 \mathrm{eV}$ is also smaller compared with the GSP's.

A thermal aging of the SCP samples did not show a significant degradation at any temperature up to $175^{\circ} \mathrm{C}$ for 4500 hours (the samples are still on test) as shown in Graph 13 . The degradation is clearly slower compared with both the GSP and the TF samples.

\subsection{Bond Resistance}

In order to test the aging behavior of bond resistance, resistance measurement samples were bonded on GSP. The samples were aged at $125^{\circ} \mathrm{C}$ and $175^{\circ} \mathrm{C}$ in air, and resistance measurements were made at room temperature using a four points resistance meter. Graph 14 shows an average for bond resistance of 10 chips. The resistance value includes resistance of a lead and a pad. The results of Graph 14 indicate that no significant change of the bond resistance was observed at temperature up to $175^{\circ} \mathrm{C}$ and for more than 8000 hours. 


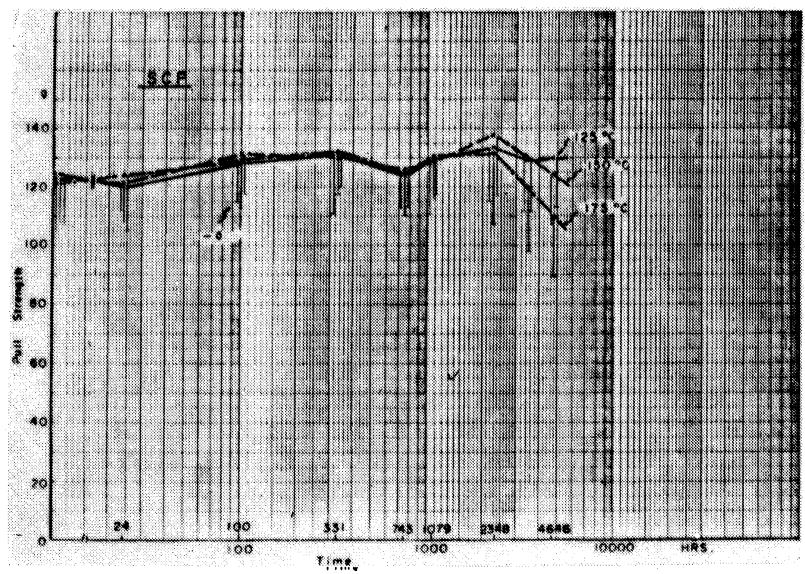

GRAPH 13 Degradation of pull strength after temperature aging.

\subsection{Failure Analysis}

As described above, enough lifetime of the GANG Bonding for gold-plated TAB outer leads was confirmed on some gold metallized substrates. After aging at $175^{\circ} \mathrm{C}$ for $2000 \mathrm{~h}$, or at $150^{\circ} \mathrm{C}$ for $8000 \mathrm{~h}$, however, a large percentage of deteriorated bond was noticed; mainly the OLB failure with low pull strength ranging from 10 to $30 \mathrm{~g}$.

A typical OLB failure of the sample aged at $175^{\circ} \mathrm{C}$ for $4500 \mathrm{~h}$ is shown in Photo 3. Photo $3 \mathrm{~A}$ is an optical photograph of the residue left on the OLB pad after the lead had been pulled to destruction, and Photo 3B shows that the lead had been pulled off with the OLB pad, leaving $\mathrm{Cu}$ exposed. Photo 4 are SEM pictures of the magnified central portion of the failed surface. The failed surface on the OLB pad side is relatively smooth and that on the lead side is very rough and porous. The height of the residue on the OLB pad and the plated

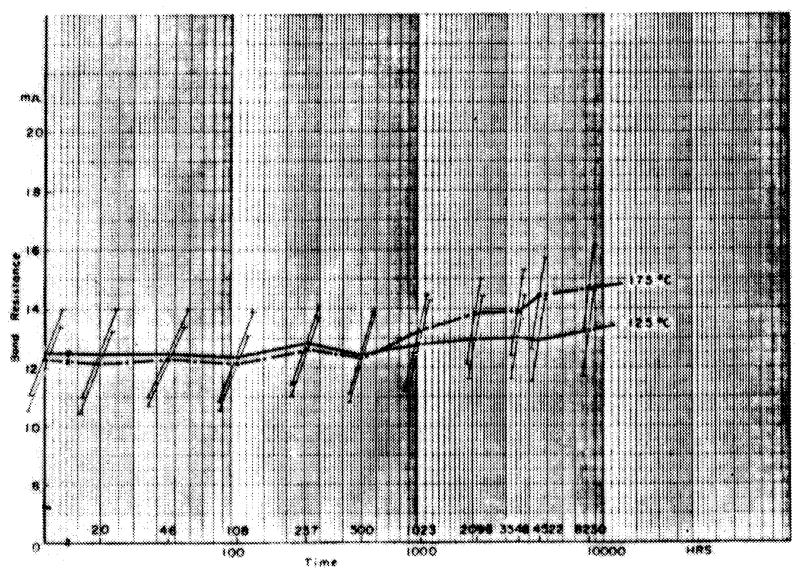

GRAPH 14 Bond resistance for GSP.

gold thickness of the companion leads were measured by a surface stylus and metallurgical cross sectioning respectively. As a result, the height was 3-10 $\mu \mathrm{m}$ and the Au thickness of lead was 4-6 $\mu \mathrm{m}$. This would mean that the failed surfaces were a little beyond the original $\mathrm{Cu}-\mathrm{Au}$ interface and in copper of the lead. Photo 5 shows energy dispersive $\mathrm{X}$-ray spectras for the failed surface on the OLB pad and the failed surface of the lead. They show that both surfaces are almost copper and a small quantity of gold exists in the failed surface of the lead. Those observations and analysis suggest that the peeling occurred at the copper rich side of the failure intermetaric and the failure is due to Kirdendall porosity, ${ }^{6}$ which could occur if one species diffuses more rapidly than the other, causing an accumulation and condensation of vacancies on one side or the other.
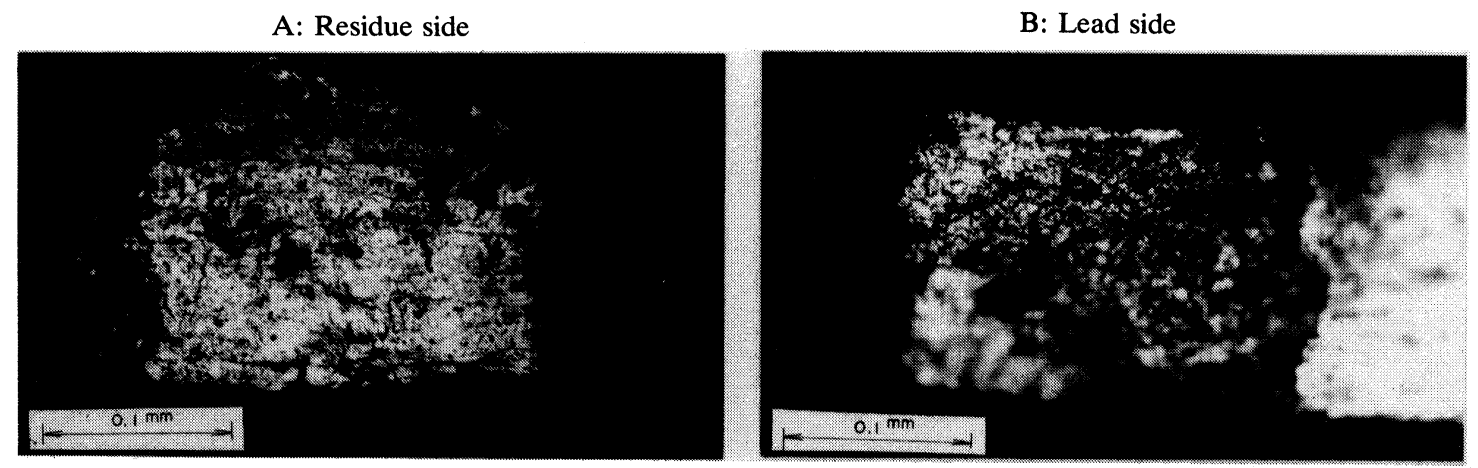

PHOTO 3 Optical photographs of failed surfaces. 
A: Residue side

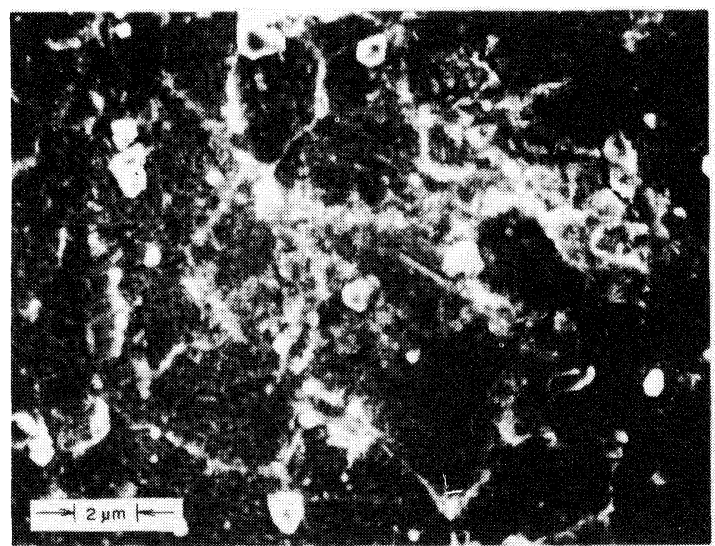

B: Lead side

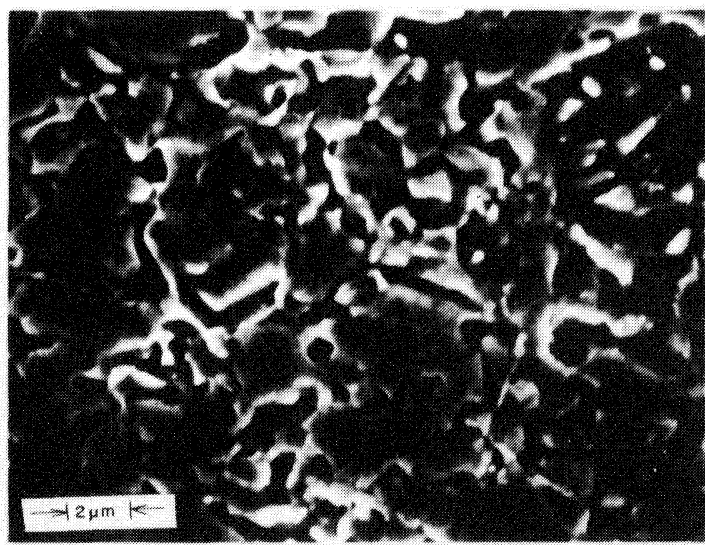

PHOTO 4 SEM pictures of failed surfaces.

A: Residue side

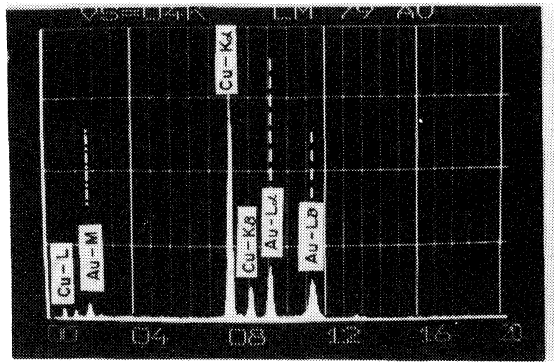

B: Lead side

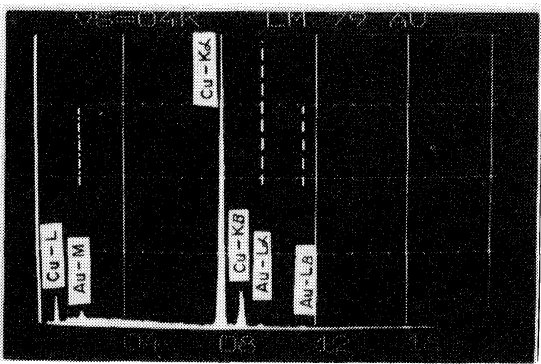

PHOTO 5 Energy dispersive X-ray spectras of failed surfaces.

\section{CONCLUSIONS}

Thermocompression GANG Bonding of gold plated TAB outer leads to some metallized ceramic substrates was evaluated. The results of the bonding parameter experiment, and the relation between pull strength and lead deformation, suggest that the TAB leads should be bonded from 15 to 65 percent lead deformation with sufficient tool temperature; although around 35 percent lead deformation would maximize the pull strength of the mean value, and the recommended parameters are established.

Initial bondability experiments using the recommended parameters show that TAB GANG Bonding has the capability of excellent bonding strength at above 120 grams with a standard deviation of less than 20 grams, which is one order of magnitude stronger than normal wire bonding, but requires the OLB pads being flat.
An evaluation of high temperature storage in air, at $175^{\circ} \mathrm{C}$ for 48 hours prior to bonding indicates no significant change of bondability on both the SCP and TF, however, in the GSP samples a slight decrease of a mean value of the strength was observed. But, they are still acceptable and chemical cleaning of the OLB pads extremely improved the bondability of the aged GSP extremely.

From the results of accelerated aging test of $125^{\circ} \mathrm{C}$, $150^{\circ} \mathrm{C}$ and $175^{\circ} \mathrm{C}$ for more than 8000 hours, Arrhenius plots were constructed, which are summarized by:

$$
\begin{aligned}
t(30 \mathrm{~g} \geq & \bar{x}-3 \sigma)= \\
& 6.5 \times 10^{-7} \exp (0.83 \mathrm{eV} / K T) \text { for the GSP }
\end{aligned}
$$

and

$$
\begin{aligned}
& t(30 \mathrm{~g} \geq \bar{x}-3 \sigma)= \\
& 3.2 \times 10^{-6} \exp (0.76 \mathrm{eV} / K T) \text { for the TF. }
\end{aligned}
$$

The effective activation energy for a pull strength 
degradation is $1.05 \mathrm{eV}$ and $0.86 \mathrm{eV}$ for the GSP and TF respectively. And no significant degradation of the electric resistance was observed on the GSP samples.

The feasibility and the high reliability of the GANG bonding for gold-plated TAB outer leads were confirmed.

\section{ACKNOWLEDGEMENTS}

The authors gratefully acknowledge to Mr. K. Baba and his staff the suggestion of the lead frame bonder; and Dr. $\mathrm{H}$. Kanai for his support and strong encouragement in the completion of this work and this manuscript.

\section{REFERENCES}

1. J. Lyman "Special Report: Film carriers Star in HighVolume IC Production" Electronics, pp 61-68 (Dec. 25, 1975).
2. T. L. Angelucci "GANG Lead Bonding Equipment, Material and Technology" Solid State Technol., pp 65-68 (Mar. 1978).

3. N. T. Panousis and P. M. Hall "Reduced Gold-Plating on Copper Leads for Thermocompression Bonding - Part I: Initial Characterization" IEEE Trans. PHP. Vol-PHP-13, No. 3. pp. 305-309 (Sep. 1977).

4. P. M. Hall and J. M. Morabito, "A Formalism for Determining Grain Boundary Diffusion Coefficients Using Surface Analysis" Surface Science, North-Holland Publishing Co., Vol. 59, pp 624-630 (1976).

5. P. M. Hall, J. M. Morabito and N. T. Panousis "Interdiffusion in the $\mathrm{Cu}-\mathrm{Au}$ Thin Film System at $25^{\circ} \mathrm{C}$ to $250^{\circ} \mathrm{C}$ " Thin Solid Films, Vol. 41, pp 341-361 (1977).

6. M. R. Pinnel and J. E. Bennett "On the Formation of the Ordered Phases $\mathrm{CuAu}$ and $\mathrm{Cu}_{3} \mathrm{Au}$ at a Copper/Gold Planar Interace" METALL. Trans. A Vol. 10A, pp 741-747 (June, 1974). 

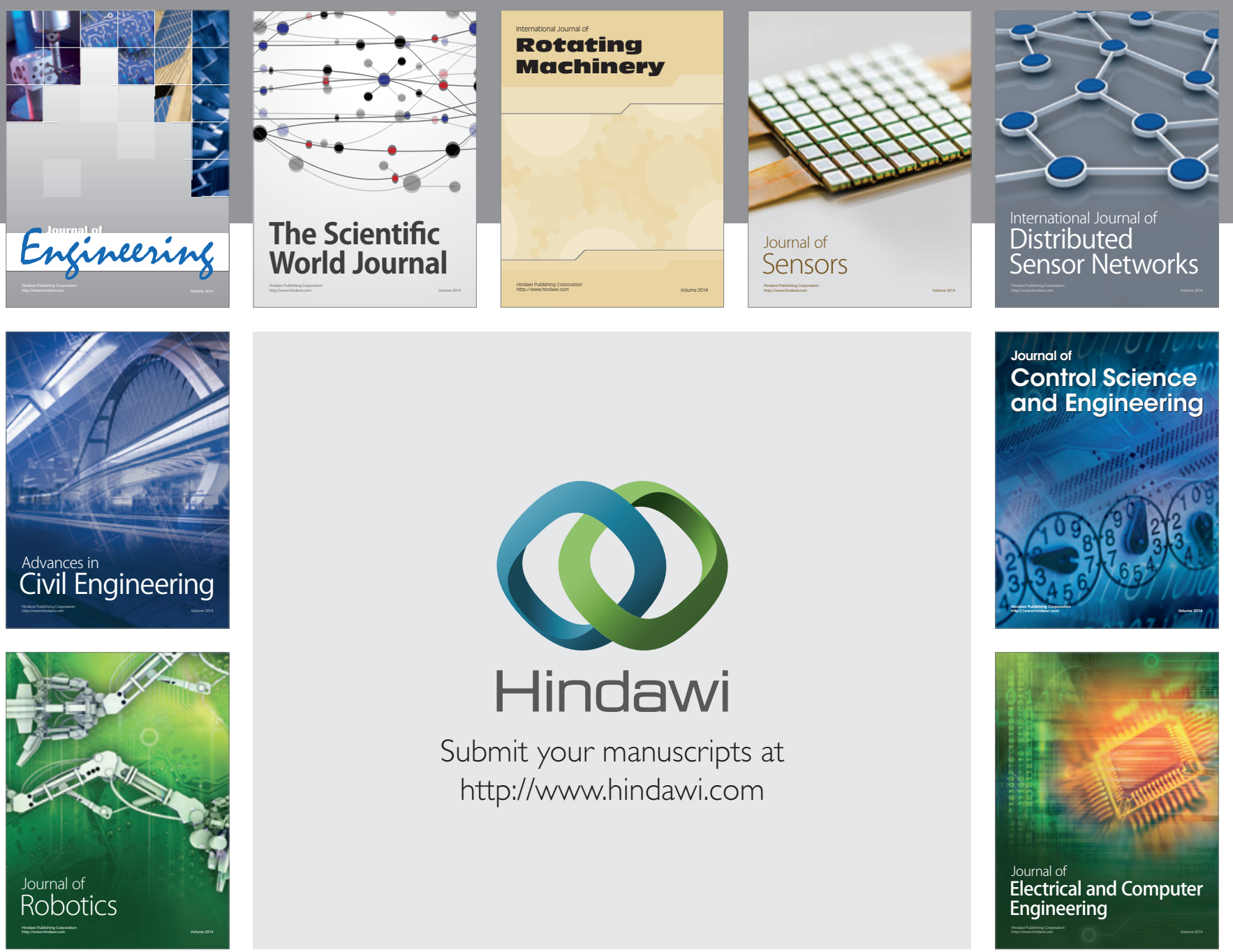

Submit your manuscripts at

http://www.hindawi.com
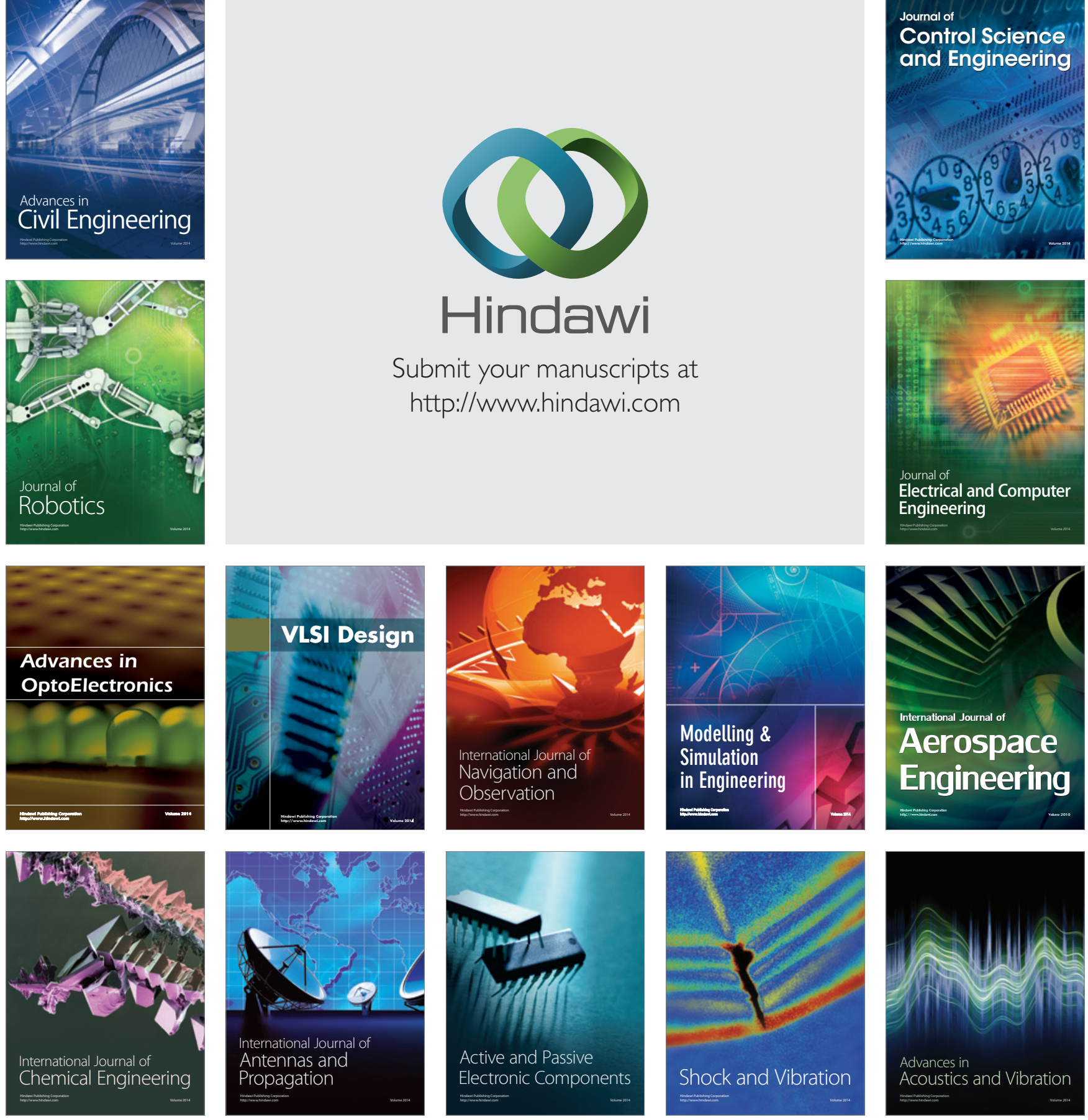